\title{
Anatomia óssea e muscular do antebraço e mão de Chrysocyon brachyurus (carnivora, canidae)*
}

\section{Bone and muscular anatomy of the antibone and hand of Chrysocyon brachyurus (carnivora, canidae)}

\author{
Saulo Gonçalves Pereira, ${ }^{* *}$ Daniela Cristina Silva Borges, ${ }^{* *}$ Eva Mendes Monteiro, ${ }^{* *}$ Sandra Regina Afonso Cardoso, ${ }^{* *}$ \\ Adriele Laurinda Silva, ${ }^{* *}$ André Luiz Quagliatto Santos****
}

\begin{abstract}
Resumo
O lobo-guará Chrysocyon brachyurus Illiger, 1815, é o maior canídeo da América do Sul, pesa cerca de 25 kg quando adulto e está ameaçado de extinção. Descrições anatômicas contribuem para a complementação das informações sobre espécies silvestres e para implicações conservacionistas, clínicas e cirúrgicas. Objetivou-se descrever os ossos e os músculos do antebraço e mão do lobo-guará. A preparação das peças foi feita a partir dos métodos usuais de dissecação, em animais preservados em solução de formol a 10\%. Os espécimes pertencem ao acervo didático do Laboratório de Ensino e Pesquisa em Animais Silvestres da UFU e são provenientes de indivíduos atropelados. Os ossos descritos foram: rádio, ulna, ossos cárpico acessório, cárpico ulnar e cárpico intermédio; ossos cárpicos I, II, III e IV; ossos metacárpicos I, II, III, IV, V; falanges proximais, falanges médias e falanges distais do primeiro ao quinto dedo. Os músculos observados foram: extensor radial do carpo; pronador redondo; braquiorradial; extensor comum dos dedos; extensor ulnar do carpo; extensor lateral dos dedos; supinador; abdutor longo do dedo I; flexor radial do carpo; flexor profundo dos dedos; flexor superficial dos dedos; flexor ulnar do carpo; pronador quadrado; interflexor; lumbricais; abdutor curto dos dedos I e II e flexor curto do dedo I.
\end{abstract}

Palavras-chave: lobo-guará, morfologia, miologia, osteologia, carnívoro selvagem

\begin{abstract}
The maned wolf Chrysocyon brachyurus (Illiger, 1815) is the largest canid in South America, weighs about $25 \mathrm{~kg}$ as an adult and is threatened of extinction. Anatomical descriptions contribute to the complementation of information on wild species and for conservation, clinical and surgical implications. The purpose of this study was to describe the bones and muscles of the forearm and hand of the maned wolf. The methodology was through the usual dissecting methods in animals preserved in $10 \%$ formalin solution. The animals belong to the didactic collection of the Laboratory of Teaching and Research in Wild Animals of the UFU and come from run over. The bones evaluated were: radius, ulna, carpal accessory, carpi ulnar and carpi intermedium; carpal bones I, II, III and IV; metacarpal bones I, II, III, IV, V; proximal phalanges, middle phalanges and distal phalanges from first to fifth finger. The muscles observed were: radial extensor carpal; pronator round; brachioradial; common extensor of fingers; ulnar carpal extensor; lateral extensor of the fingers; supinator; abductor long finger I; flexor carpi radialis; flexor deep fingers; superficial flexor of the fingers; ulnar flexor of the carpus; square pronator; interflexor; lumbrils; short abductor of fingers I and II and short flexor of finger I.
\end{abstract}

Keywords: Wolf manure, morphology, myology, osteology.

\section{Introdução}

O lobo-guará Chrysocyon brachyurus (Illiger, 1815) é um canídeo selvagem que ocorre, sobretudo, em áreas de cerrado e de campos abertos no Brasil, norte da Argentina, oeste da Bolívia e do Paraguai (Dietz, 1984, 1985; Rodden et al., 2007; 2012; Pereira et al., 2016).

Os membros torácicos de C. brachyurus são longos e seu passo é classificado como cursorial digitígrado, postura única entre os canídeos. Tal padrão difere de outros canídeos que pisam de forma diagonal ou com pegadas progressivas. Os dedos são abertos, porém com os dedos III e IV unidos, e as pegadas do membro torácico têm entre 7 e $9 \mathrm{~cm}$ de comprimento e $5,5 \mathrm{e}$ $7 \mathrm{~cm}$ de largura (Carvalho, 1976; Shaw, 1995; Motta-Junior et al., 1996; Borges e Tomás, 2004; Hildebrand e Goslow, 2006).

C. brachyurus consta no Apêndice II da CITES (Convention on International Trade in Endangered Species of Wild Fauna and Flora) como ameaçado de extinção. Atualmente é considerado Vulnerável (VU) na Lista Vermelha de Espécies Ameaçadas da IUCN (International Union for Conservation of Nature) e ICMbio (Instituto Chico Medes de Biodiversidade) (Chiarello et al., 2008; Rodden et al., 2012; Paula et al., 2013; Brasil, 2014).

\footnotetext{
*Recebido em 10 de fevereiro de 2019 e aceito em 19 de novembro de 2019.

** Laboratório de Ensino e Pesquisa em Animais Silvestres (LAPAS); Universidade Federal de Uberlândia (UFU). Faculdade Patos de Minas.

${ }^{* * *}$ Laboratório de Ensino e Pesquisa em Animais Silvestres (LAPAS); Universidade Federal de Uberlândia (UFU). Faculdade Cidade de João Pinheiro.

**** Laboratório de Ensino e Pesquisa em Animais Silvestres (LAPAS); FAMEV. Universidade Federal de Uberlândia - UFU.

Autora correspondente: saulobiologo@yahoo.com.br.
} 
Descrições anatômicas macroscópicas são de fundamental importância para a caracterização de espécies e também para a comparação entre elas. Importantes ainda, para o agrupamento taxonômico, para intervenções de ordem clínica-cirúrgica, como subsídio didático, evolutivo, conservacionista e identificação de cadáveres (Ribeiro, 2002; Aversi-Ferreira et al., 2006, Johnson, 2008; Lima et al., 2010; Ribeiro et al., 2016). Visto a importância das descrições anatômicas para complementação das informações sobre espécies silvestres e, ainda considerando a importância de C. brachyurus para o meio ambiente, objetivouse descrever os ossos e os músculos do antebraço e mão do lobo-guará.

\section{Material e métodos}

Foram utilizados os membros torácicos de quatro indivíduos adultos de $C$. brachyurus, (08 membros), sendo dois machos e duas fêmeas, fixados em solução aquosa de formaldeído a $10 \%$ e conservados em cubas opacas com a mesma solução fixadora. Estes exemplares fazem parte do seu acervo didáticocientífico permanente do Laboratório de Ensino e Pesquisa em Animais Silvestres da Universidade Federal de Uberlândia (LAPAS-UFU). Ressalta-se que nenhum animal foi eutanasiado para esta pesquisa e a causa da morte foi por atropelamento, em estradas da região do Triângulo Mineiro e Alto Paranaíba, Minas Gerais, por isso a idade dos animais não pôde ser definida. recomendados pelo International Committee on Veterinary Gross Anatomical Nomenclature (2012). A comparação dos achados anatômicos baseou-se principalmente com a anatomia dos cães-domésticos e também para a verificação das variações anatômicas. As imagens foram registradas com câmera digital Nikon Coolpix L840 e as fotografias foram tratadas pelo software Photoshop CS (2012®).

\section{Resultados e discussão}

\section{Osteologia - Ossos do antebraço}

Os dois ossos do antebraço são o rádio e a ulna (Figura 1), que articulam-se proximalmente com o côndilo do úmero e distalmente com os ossos do carpo. Esses ossos entrecruzam-se obliquamente onde a extremidade proximal da ulna localiza-se caudalmente ao rádio e a epífise distal localiza-se lateralmente ao rádio.

O osso rádio (Figura $1, \mathrm{~B}, \mathrm{C}$ e D), de Chrysocyon brachyurus é o osso mais curto do antebraço, articula-se com a ulna proximalmente em sua face caudal e distalmente com o carpo. Destacam-se três segmentos: cabeça, colo, corpo e tróclea. É um osso em forma de bastão e espessura na região medial aumenta no sentido laterocaudal, configuração encontrada em outros canídeos (Moro-Rios, 2008).
Inicialmente, para a descrição muscular retirou-se pele e excesso de tecido adiposo. Os músculos foram expostos e dissecados, segundo as técnicas usuais utilizadas em anatomia macroscópica de acordo com o "Guia de dissecação do cão" (Evans e De La Hunta, 1994). Para observação dos músculos profundos, bem como das inserções musculares, a musculatura superficial teve seus ventres ou tendões seccionados, quando necessário. A ação hipotética dos músculos foi estabelecida a partir da apreciação de sua morfologia, topografia e de seus pontos de fixação ao esqueleto. Para a descrição dos ossos, assim como de seus acidentes, os animais foram macerados por cocção em balde plástico de 20 litros, com ebulidor elétrico 1000 W (Dwolts 220v) e, posteriormente, depositados em solução de peróxido de hidrogênio (50\% PA) por 6 horas (Rodrigues, 1973). Depois de limpos e secos, os ossos foram identificados e minuciosamente descritos.

A pesquisa está de acordo com a Instrução Normativa 03/2015 do Instituto Brasileiro do Meio Ambiente e dos Recursos Naturais Renováveis (IBAMA), e está protocolada pela Comissão de Ética na Utilização de Animais - CEUA-UFU 087/16 com dispensa. Todavia, autorizada pelo CEUA do Centro Universitário de Patos de Minas (UNIPAM 07/2017), pelo Instituto Chico Mendes de Conservação da Biodiversidade (ICMBio/ SISBIO 49266-1) e pelo termo de cooperação 002/2011 IBAMA/UFU/LAPAS.

Os dados foram discutidos e as descrições estão apresentadas de acordo com os termos

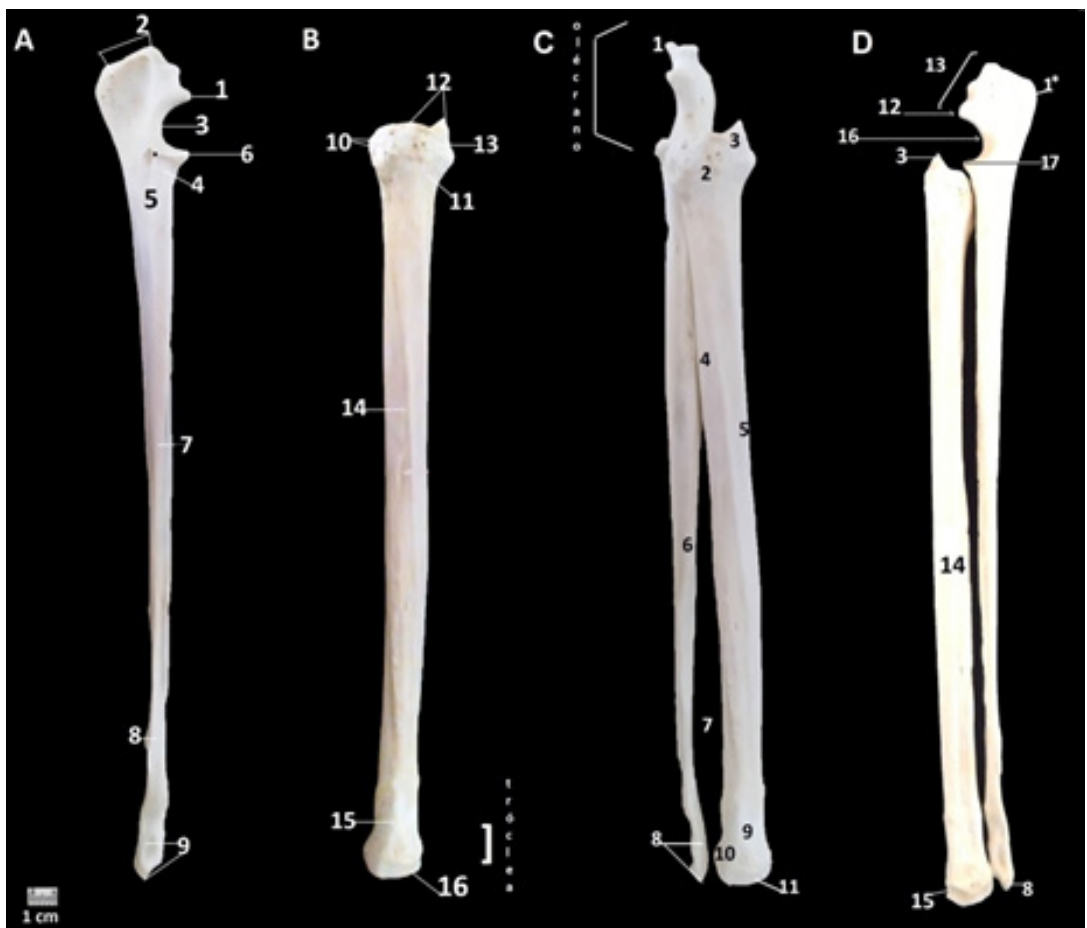

Figura 1: A) ulna de $C$. brachyurus face medial. B) rádio de $C$. brachyurus face cranial: 1. processo ancôneo; 2. túber do olécrano; 3 . incisura troclear; 4. incisura radial; 5. tuber da ulna; 6. processo coronoide medial; 7. margem interóssea; 8 . circunferência articular distal; 9. processo estiloide da ulna; 10 . colo da rádio; 11 . tuberosidade do rádio; 12 . fóvea da cabeça do rádio (troclear); 13. circunferência articular; 14. margem cranial; 15. incisura ulnar 16. tróclea do rádio. C) rádio e ulna esquerda de $\boldsymbol{C}$. brachyurus face cranial. D) ulna e rádio esquerda face lateral de $\boldsymbol{C}$. brachyurus: 1 . tuber do olécrano, $1^{*}$ tuber do olécrano margem caudal; 2. Tuberosidade do rádio; 3 . fóvea da cabeça do rádio; 4 . margem lateral; 5. margem medial; 6. corpo da ulna; 7. espaço interósseo antebraquial distal; 8. processo estiloide da ulna; 9. margem do sulco lateral na vista cranial; 10. incisura ulnar; 11. face articular; 12. processo ancôneo, 13. olécrano, 14. corpo do rádio, 15 . processo estiloide do rádio na vista craniomedial, 16. incisura troclear; 17. processo coronoide lateral. 
A extremidade proximal (Figura 1, B, C e D) é constituída por cabeça, colo e tuberosidade do rádio. O colo da cabeça do rádio encontra-se distalmente à tuberosidade do rádio, sendo liso e côncavo, na tuberosidade do rádio se insere o tendão do músculo bíceps braquial. Nesta região encontra-se, também, a fóvea da cabeça do rádio (parte troclear), que é uma superfície articular ovalada e côncava, sendo em lobo-guará menos côncava que em cães-domésticos. Essa região faz a articulação com a tróclea do úmero.

A face caudal do osso rádio apresenta a incisura radial para a articulação com a ulna. Esse osso tem a função, em carnívoros, de facilitar a supinação e tal ação auxilia no deslocamento em longas distâncias e na aceleração (St. Clair, 1986; Shaw, 1995; König e Liebich, 2016).

O corpo do rádio (Figura 1, B, C e D) é comprimido em sentido craniocaudal, apresentando-se reto ao longo de todo o seu comprimento, bem como em sua circunferência, diferentemente do cão-doméstico qual é levemente convexo. Consta de uma face cranial e uma caudal, uma margem lateral e uma medial. Essa margem aloja os músculos extensores e flexores do carpo e dos dedos, bem desenvolvidos nessas regiões. Essas características sugerem uma adaptação para força em seus membros torácicos, assim como para a aceleração (Nowak, 1999).

A extremidade distal do rádio (Figura 1, B, C e D) forma a tróclea, sendo a superfície articular cárpica. Nessa região, na superfície lateral está a incisura ulnar que é a área de articulação com a ulna. Já na superfície medial, encontra-se o processo estiloide do rádio, sendo uma estrutura pouco pontiaguda que dá inserção a vários ligamentos, como descrito para outros canídeos (Evans e De La Hunta, 1994; König e Liebich, 2016). Comparando-se com o rádio do cão-doméstico, no lobo-guará este osso é mais afinado e não está fundido à ulna (Frandson, 2005; Getty, 2013).

A ulna (Figura $1 \mathrm{~A}, \mathrm{C}$ e D) de $C$. brachyurus é o maior dos ossos do antebraço, sua extremidade proximal localiza-se caudolateralmente à extremidade proximal do rádio. Articula-se com a tróclea do úmero por meio da incisura troclear e com o rádio pela incisura radial, formando a articulação do cotovelo. $A$ ulna apresenta duas extremidades e um corpo. A extremidade proximal localiza-se caudalmente ao rádio e articula-se com o mesmo por meio da incisura radial. O corpo da ulna estende-se caudolateralmente até ao nível da extremidade distal do rádio. $\mathrm{Na}$ extremidade distal, a ulna é lateral e articula-se com o rádio medialmente, e com os ossos cárpico acessório e cárpico ulnar distalmente. A ulna é um osso alongado que afina-se da extremidade proximal para distal em C. brachyurus, sendo estas características bastantes distintas comparando-se a outros canídeos.

A extremidade proximal (Figura $1 \mathrm{~A}, \mathrm{C}$ e D) da ulna constitui o olécrano, que possui quatro faces (medial, lateral, proximal e caudal). É uma estrutura côncava e lisa medialmente, e convexa e áspera lateralmente. Articula-se com a tróclea do úmero na incisura troclear, sendo esta uma grande depressão formada pelo olécrano e o processo coronoide, servindo de articulação com a tróclea do úmero. Tais estruturas formam o cotovelo que, por sua vez, atua como uma alavanca para os músculos dessa região. Essa conformação dá celeridade ao passo e, sobretudo, aceleração na corrida e saltos, assim como em outros animais digitígrados corredores (Evans e De La Hunta, 1994; Hildebrand e Goslow, 2006).

Ainda no olécrano, sua extremidade proximal denomina-se tuber do olécrano. Nesta região, encontram-se sulcos para a inserção a diversos músculos do cíngulo escapular e a origem de quase todos os músculos do antebraço, dando o suporte para o movimento de alavanca para o braço (Evans e de La Hunta, 1994, Costa e Schossler, 2002; Ferrigno et al., 2004).

Os processos coronoídes estão localizados ventral e bilateralmente à incisura troclear. Ainda na extremidade proximal, localiza-se o processo ancôneo, sendo este arredondado, diferentemente dos cães-domésticos nos quais é pontiagudo (Schebitz e Wilkens, 2000).

O corpo da ulna (Figura 1 A, C e D) apresenta-se com formato triangular e afina-se em direção a extremidade distal, mudando sua característica de triangular para irregular. Este comportamento morfológico foi observado em todos exemplares analisados. A margem interóssea é irregular, porém bastante nítida na região distal de ambos os ossos. Esta margem forma o espaço interósseo, que é bastante evidente e abriga a artéria interóssea caudal. Tal espaço permite ao lobo-guará executar movimentos de rotação, fato descrito nos demais carnívoros, porém de grande importância para o lobo-guará para o desenvolvimento de seu passo (Dyce et al., 2010; Getty 2013).

A extremidade distal da ulna (Figura 1 A, C e D) corresponde à cabeça, onde é notada a projeção de um processo estiloide no sentido ventrolateral. Observa-se que este processo se articula medialmente com o rádio, e caudalmente com os ossos do carpo (cárpico ulnar e cárpico acessório), assim como em cães-domésticos, porém bem mais afinada em lobo-guará. Tal conformação permite ao lobo-guará uma ação de supinação dos músculos da mão com melhor eficiência (Evans e De La Hunta 1994; Costa e Schossler, 2002).

O ângulo do antebraço relaciona-se com a força e postura do C. brachyurus (Hildebrand e Goslow, 2006). O antebraço do lobo-guará é longo, que permite a esse animal uma melhor acuidade visual, o que é provavelmente uma adaptação para o deslocamento em áreas abertas com predominância de gramíneas (Silvero-Zubiri, 2009; Paula e Gambarini, 2013b).

\section{Ossos da mão}

Em C. brachyurus há sete ossos no carpo, três na fileira proximal e quatro na fileira distal. Segundo König e Liebich (2016), os ossos do carpo apresentam-se de maneira diferente em cada espécie de animal. Na fileira proximal dos ossos cárpicos do lobo-guará, estão o cárpico ulnar, cárpico intermédio e cárpico acessório, padrão semelhante ao dos cães domésticos (Cbkc, 2003; Hildebrand e Goslow, 2006).

O osso cárpico intermédio (Figura 2) é o maior dos ossos da fila proximal e está localizado na face medial. É, aparentemente, a fusão do osso intermédio e do osso radial como em cães, o que pode ser inferido também para o lobo-guará, tendo em vista que existem apenas três ossos na região proximal do carpo (König e Liebich, 2016).

O osso cárpico ulnar (piramidal) (Figura 2) é o mais lateral da fileira proximal articula-se proximalmente com o rádio e a ulna e láteropalmarmente com o cárpico acessório. É extenso e fornece uma estabilidade para a postura digitígrada do animal 
(St. Clair, 1986). Esse osso projeta-se sob a pele, fazendo uma proeminência externa na articulação na região ventral do carpo.

O osso cárpico acessório (pisiforme) (Figura 2) é tubular, expandindo-se nas extremidades. $\mathrm{Na}$ face palmar, articula-se com o processo estiloide da ulna e com o osso cárpico ulnar, sendo que essa conformação é também encontrada em outros canídeos (König e Liebich, 2016).

$\mathrm{Na}$ fileira distal do carpo estão dispostos os quatro ossos cárpicos, assim numerados de medial para lateral I, II, III e IV. O osso cárpico I (trapézio) (Figura 2) articula-se lateralmente com o osso cárpico II e distalmente com o osso metacárpico I. O osso cárpico II (trapezoide) articula-se com o osso metacárpico II. O osso cárpico III (capitato) (Figura 2) articula-se com o osso metacárpico III. O osso cárpico IV (hamato) (Figura 2) articula-se com os ossos metacárpicos IV e V.

A ordem e o formato de cada osso cárpico são semelhantes aos demais canídeos (Evans e De La Hunta, 1994; Cbkc, 2003; Hildebrand e Goslow, 2006; Getty, 2013; Pinheiro, 2014; König e Liebich, 2016). Os ossos da fileira distal são bastante sobrepostos. Tendo em vista o fato de a descrição ter sido realizada em animais adultos, infere-se que tal conformação, de acordo com Neumann (2001), dá vantagens à amplitude de movimentos, melhorando a atividade de rotação e aceleração do passo, padrão importante na dinâmica corporal de $C$. brachyurus.

Em C. brachyurus há cinco ossos metacárpicos (Figura 2), presentes em cada membro torácico. São ossos proeminentes, pois a postura digitígrada para os canídeos apresenta ossos metacarpais desenvolvidos para sustentarem o peso do animal (Hidebrand e Goslow, 2006).

Todos os ossos metacárpicos têm em sua extremidade distal uma tróclea, para articulação com as falanges proximais com presença de rugosidades. O peso do animal repousa somente nos dedos. Tal conformação demonstra que os ossos metacárpicos estão adaptados para o passo digitígrado. Os ossos metacárpicos apresentaram em sua base proeminências para fixação de músculos e ligamentos. O coxim (Figura 3 - 9) é bastante proeminente, fixando uma pegada muito característica (Borges e Tomás, 2004; Hidebrand e Goslow, 2006).

Todos os ossos metacárpicos são levemente comprimidos dorsopalmarmente, sendo que os ossos metacárpicos II e V (Figura 2) possuem três faces nítidas, principalmente nas extremidades proximais, com forma aproximadamente triangular. Os metacarpos III e IV (Figura 2) têm forma semelhante a um quadrilátero por apresentar quatro faces aproximadamente bem definidas.

Já o osso metacárpico I (Figura 2), apresenta um formato irregular, sendo menor que os demais, assemelhando-se a um quadrilátero em suas extremidades e arredondado em seu corpo. O primeiro osso metacárpico é o mais medial ao se palpar o animal sem macerar, sendo proporcionalmente menor que os demais, conhecido também como ergot e eventualmente toca o solo.

Os ossos metacárpicos III e IV (Figura 2) são semelhantes entre si, apresentam-se maiores que os demais e são os responsáveis pelo passo digitígrado. Tal padrão também é comum para o lobo-cinzento (Canis lupus Lineu, 1758) (Serpell, 1995), cachorro-selvagem-africano (Lycaon pictus Temminck, 1820) (Hartstone-Rose et al., 2010) e para outros animais digitígrados (Moro-Rios et al., 2008).

O osso metacárpico II é menor que o III e o IV, entretanto, auxilia no passo digitígrado do animal. Por sua vez, o osso metacárpico $\mathrm{V}$ (Figura 2) é levemente mais curto que o II, porém é mais espesso, principalmente na sua extremidade proximal. Essa conformação pode estar relacionada à inserção do M. extensor ulnar do carpo.

Os dedos II, III, IV e V (Figura 2) são compostos por três falanges (proximal, média e distal, respectivamente). Já o dedo I possui

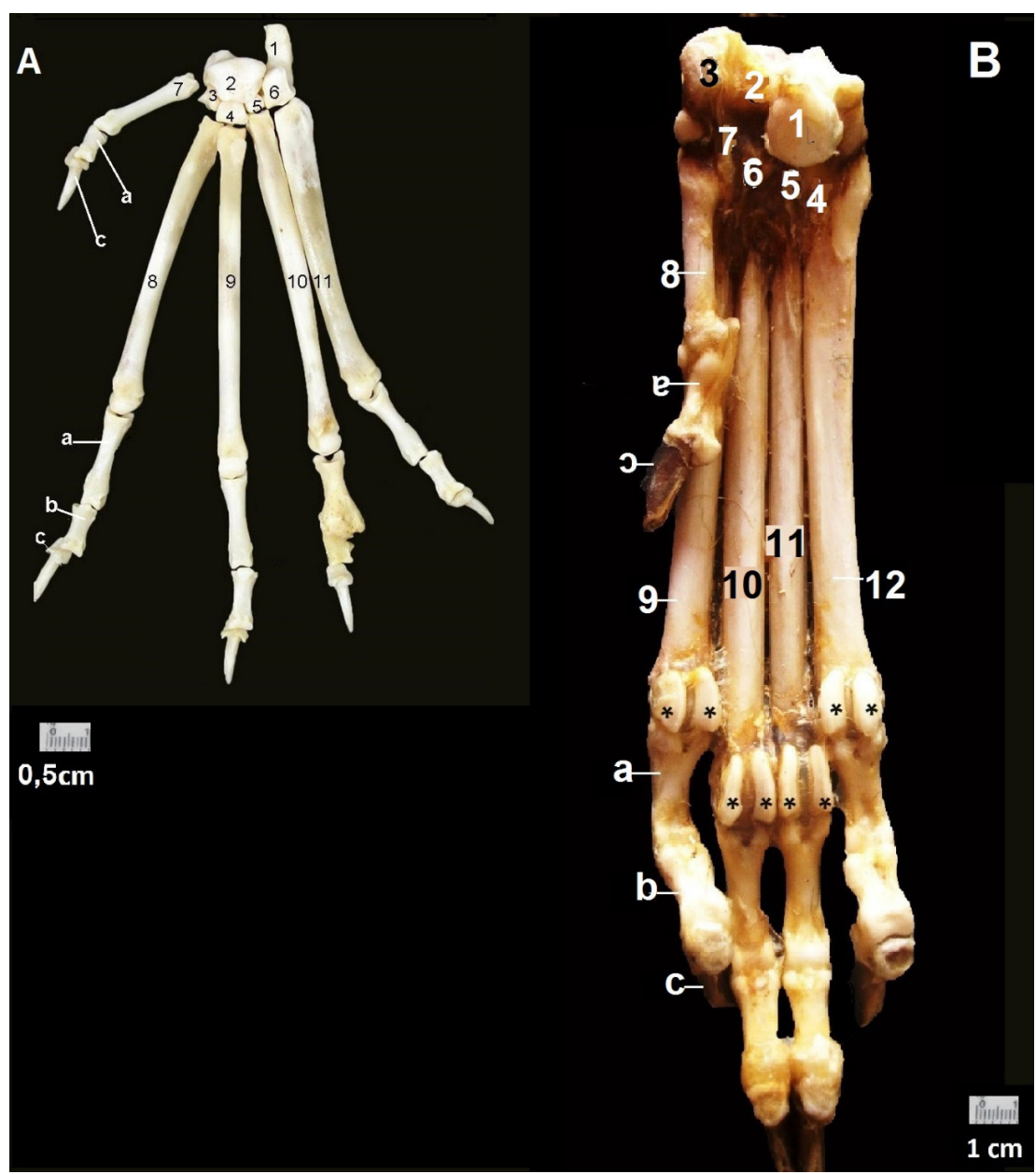

Figura 2: A) vista dorsal da mão de C. brachyurus. 1. cárpico acessório; 2. cárpico intermédio; 3. cárpico I; 4. cárpico II; 5. cárpico III; 6. cárpico IV; 7 metacárpico I; 8. metacárpico II; 9. metacárpico III; 10. metacárpico IV; 11. metacárpico V; a) falanges proximais do primeiro ao quinto dedo; b) falanges médias do segundo ao quinto dedo; c) falanges distais do primeiro ao quinto dedo. B) vista palmar de C. brachyurus: 1. cárpico acessório; 2. cárpico ulnar 3. cárpico intermédio; 4. cárpico $N$; 5. cárpico III; 6. cárpico II; 7. cárpico / e sesamoides proximais; 8. metacárpico I; 9. metacárpico II; 10. metacárpico III; 11. metacárpico IV; 12. metacárpico V; a) falanges proximais do primeiro ao quinto dedo; b) falanges médias do segundo ao quinto dedo; c) falanges distais do primeiro ao quinto dedo *sesamoides. 
duas falanges (proximal e distal), o que impede que o mesmo toque o solo durante a caminhada. Este padrão também é observado em cães domésticos, cachorro-do-mato (Cerdocyon thous Linnaeus, 1766), paca (Cuniculus paca Linnaeus, 1766), Lycaon pictus, raposinha-do-campo (Lycalopex vetulus Lund, 1842) e Canis lupus (Evans e De La Hunta, 1994; Serpell, 1995; Oliveira, 2007; Hartstone-Rose, et al., 2010; Getty, 2013).

As falanges proximais e médias são retas na margem lateral. Possuem na extremidade proximal duas tuberosidades e uma concavidade, formando um sulco que se articula com o metacarpo correspondente. Observa-se que são ossos proeminentes, o que segundo Paranaíba et al. (2012), na postura digitígrada, o peso do corpo é amparado apenas pelas falanges, reduzindo dessa maneira o atrito e aumentando o alcance do passo.

Assim como em cães domésticos, as falanges distais de $C$. brachyurus apresentam uma base proximal e uma cabeça distal, que no caso é pontiaguda, no formato da unha a partir da crista ungueal, na região ventral. A região dorsal é arredondada e cônica. O processo ungueal projeta-se dessas falanges, formando a unha que é permanente, semelhante aos cães domésticos (St. Clair, 1986; Evans e De La Hunta, 1994; Getty, 2013).

Os ossos sesamoides proximais palmares, possuem formato virgular e são encontrados aos pares em cada articulação metacarpofalângea dos dedos II, III, IV e V. Os ossos sesamoides dorsais são encontrados na mesma articulação, um em cada dedo, como em canídeos. Os ossos sesamoides dão estabilidade aos músculos (Evans e De La Hunta 1994; König e Liebich, 2016).

\section{Miologia}

Os músculos craniolaterais do antebraço de $C$. brachyurus são extensores do carpo e dedos, e são inervados pelo ramo profundo do nervo radial. A maioria tem origem no epicôndilo lateral do úmero (Budras e Fricke, 1995).

O M. extensor radial do carpo em $C$. brachyurus (Figuras 3 e 4) é um músculo que se apresenta alongado, sendo o maior do grupo extensor. Sua origem é no epicôndilo lateral do úmero, estendendo-se até ao nível da crista supracondilar lateral esse osso. Sua inserção ocorre por meio de dois tendões, um localizado na região média na face lateral do osso rádio, e outro nas tuberosidades dorsais do osso metacárpico II, sob uma forte aponeurose. Infere-se que seja responsável pela extensão da articulação do carpo, assim como descrito para Cerdocyon thous (Vaz et al., 2011).

O M. extensor comum dos dedos (Figuras 3 e 4) está localizado profundamente, em sua grande parte, sob o M. extensor radial do carpo. Sua origem é no epicôndilo lateral do úmero, juntamente com o músculo extensor radial do carpo, por meio de um pequeno tendão. Forma-se um forte tendão para sua inserção no sulco lateral na epífise distal do osso rádio, e também na falange distal de cada um dos quatro dedos (I a V). Tem a função de estender os dedos, tais conformações também são comuns a cães domésticos e mão-pelada Procyon cancrivorus Cuvier, 1798, e quati Nasua nasua Linnaeus 1766 (Evans e De La Hunta, 1994; Lima et al., 2010; Martins et al., 2013).
O M. braquiorradial (Figura 4) está aderido, em todos os espécimes dissecados, ao M. extensor radial do carpo, sendo bastante fino. Origina-se no terço distal da face lateral na crista supracondilar lateral do rádio e insere na região distal do rádio. Evans e de Lahunta (1994); Santos-Junior et al. (2002); Dyce et al. (2010) e Getty (2013) argumentam que este músculo é frequentemente ausente em cães, além de ser pouco desenvolvido, caso esteja presente. Já segundo König e Liebich (2016), tal musculo é desenvolvido nos gatos, acredita-se que por ser importante no hábito escalador. Por sua vez, Lima et al. (2010); Vaz et al. (2011) apresentam que o M. braquiorradial está presente em outros carnívoros silvestres, como em cachorrodo-mato-de-orelhas-curtas (Atelocynus microtis Sclater, 1883), Cerdocyon thous e Procyon cancrivorus.

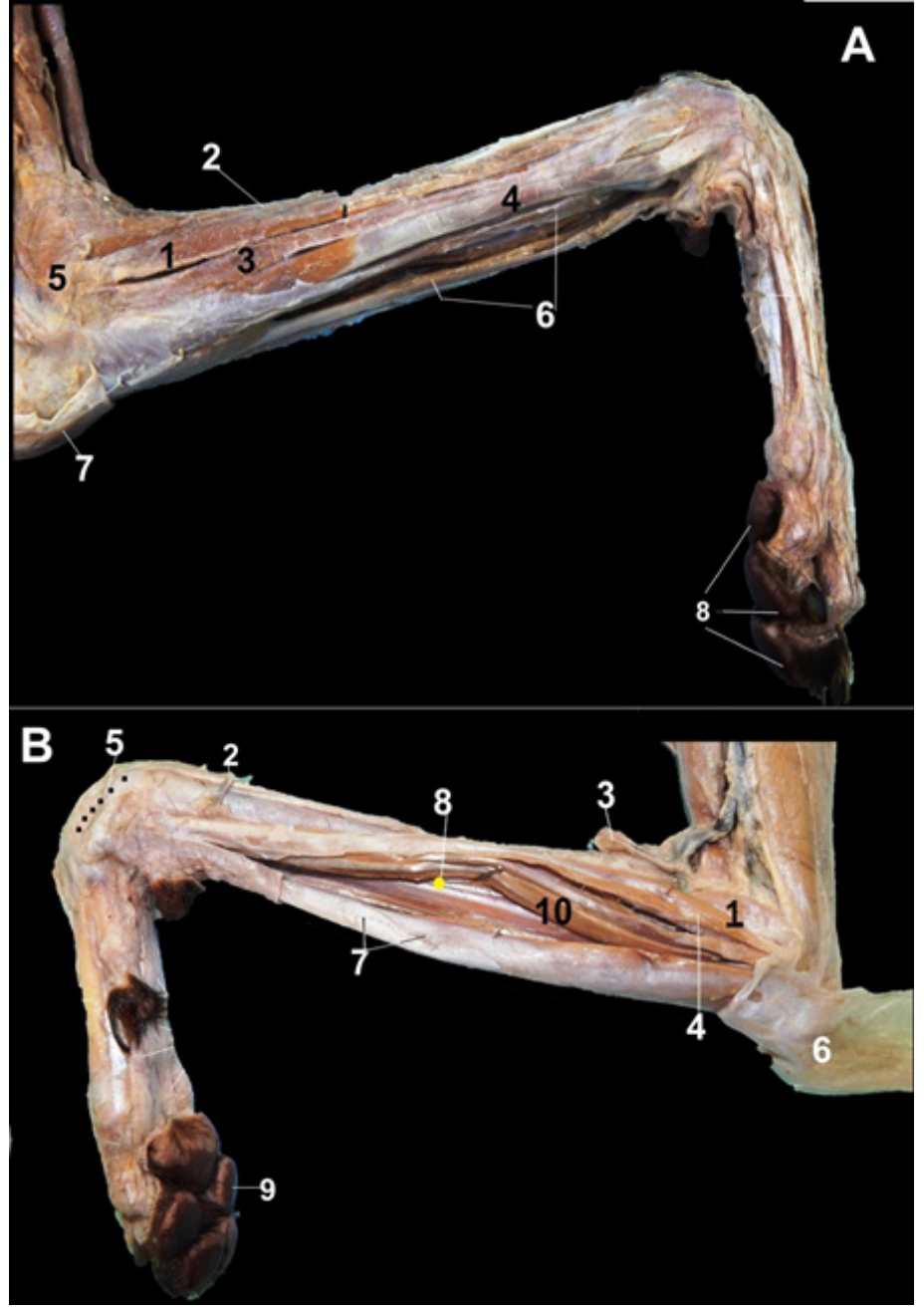

Figura 3: A) Antebraço e mão de $\boldsymbol{C}$. brachyurus face lateral: 1. M. extensor comum dos dedos; 2. M. extensor radial do carpo; 3. M. extensor lateral dos dedos; 4. M. extensor ulnar do carpo; 5. M. supinador; 6. M. flexor ulnar do carpo; 7. fáscia do antebraço; 8. coxins. B) Antebraço e mão de $\boldsymbol{C}$. brachyurus vista medial: 1. M. pronador redondo; 2. Veia Cefálica; 3. M. Braquiorradial; 4. M. flexor radial do carpo; 5. M. abdutor longo do dedo I; 6. Fáscia mediocaudal do antebraço; 7. M. flexor superficial dos dedos; 8. M. pronador quadrado; 9. Coxim; 10. M. flexor profundo dos dedos (3 cabeças).
O M. supinador (Figura 3) é um músculo pouco evidente que se origina no epicôndilo lateral, por um pequeno tendão. Insere-se na face cranial do corpo do osso rádio, em seu terço médio. 
Infere-se que sua ação seja supinar a mão, o que é de grande importância para o passo do lobo-guará, tendo em vista a ação de corrida e escalada (Carvalho, 1976).

O M. abdutor longo do dedo I (Figura 4) é um músculo muito delgado e está localizado no espaço interósseo entre o rádio e a ulna, assim como verifica-se em cãesdomésticos (Getty, 2013). Origina-se na face lateral imediatamente ventral ao processo coronoide lateral ao nível do espaço interósseo antebraquial proximal. Sua inserção ocorre por um tendão no terço proximal do osso metacárpico I. O músculo abdutor longo do dedo I abduz o primeiro dedo e o estende (Evans e De La Hunta, 1994; Lima et al., 2010; Getty, 2013).

O M. extensor ulnar do carpo (Figura 3) localiza-se na região caudal do antebraço. Sua origem é junto ao M. extensor comum dos dedos, no epicôndilo lateral do úmero. Seu ventre muscular é pequeno e sua maior parte é constituída de um forte tendão que se insere no terço proximal e face lateral do osso metacárpico V, assim como descrito para outros canídeos (Evans e De La Hunta, 1994; Cbkc, 2003; Hildebrand e Goslow, 2006; Relva et al., 2010; Getty, 2013; Pinheiro, 2014).

O M. extensor lateral dos dedos (Figura 4) encontra-se localizado profundamente ao M. extensor comum dos dedos em sua parte lateral, estando aderido a este. Tais músculos apesar de unidos têm origens diferentes. O M. extensor lateral dos dedos tem sua origem no epicôndilo lateral do úmero, profundo ao ligamento colateral ulnar no cotovelo, e sua inserção ocorre na falange distal dos dedos III, IV e V, semelhante ao encontrado por Martins et al. (2013) em Nasua nasua.

O M. extensor dos dedos I e II localiza-se profundamente aos músculos extensores. É um músculo pouco evidente, alongado e fino, que se origina no terço médio da superfície dorsal da ulna, profundamente aos músculos extensores do carpo, inserindose nas extremidades distais dos ossos metacárpicos e nas falanges proximais dos dedos I e II, com a função de estender a articulação metacarpofalângea. Configuração semelhante é observada em cãesdomésticos e em Procyon cancrivorus (Paranaíba et al., 2012; Getty, 2013).

O M. pronador redondo (Figura 4), apesar de ser assim denominado, em lobo-guará não é arredondado. Cruza parcialmente a articulação do cotovelo e localiza-se entre os músculos extensor radial do carpo cranialmente, e flexor radial do carpo caudalmente. Sua origem está no epicôndilo medial do úmero e insere-se na margem medial do rádio, em seu terço proximal. Infere-se, por meio da disposição e localização desse músculo, que a pronação do antebraço e mão tenha relação com os movimentos de deslocamento e manipulação de alimentos, assim como para cãesdomésticos (Stanley, 2002), Cerdocyon thous (Rodrigues et al., 2013) e Nasua nasua (Santos et al., 2010a).

Com relação à musculatura extensora de C. brachyurus observa-se que, de acordo com a posição dos músculos dissecados e identificados, estes apresentam a função de estender a articulação do carpo, estender as articulações metacarpofalângeas e interfalângicas proximal, média e distal quando presentes. Tais dados também são observados em outros canídeos (Evans e De La Hunta, 1994; König e Liebich, 2016), em Nasua nasua (Santos et al., 2010b; Paranaíba et al., 2012), em Atelocynus microtis e em Cerdocyon thous (Vaz et al., 2011).
Os músculos caudomediais do antebraço são os flexores do carpo e dedos, e estão inervados pelos nervos mediano e ulnar (Budras e Fricke, 1995).

O M. flexor superficial dos dedos (Figura 4) está localizado na parte caudal do antebraço, sendo um músculo alongado e protuberante. Em C. brachyurus surge por um fino tendão a partir do epicôndilo medial do úmero. Insere-se por um tendão fino no osso cárpico acessório, a partir dessa primeira inserção o tendão subdivide-se em quatro tendões bastante finos que se inserem, por fim, nos ossos metacárpicos II, III, IV e V e nas faces palmares das falanges médias, tal configuração é similar a outros canídeos, porém ressalta-se que os tendões de inserção são bastante finos (Stanley, 2002; Dyce et al., 2010).

O M. flexor radial do carpo (Figuras 3 e 4) localiza-se na superfície média do antebraço, entre os músculos pronador redondo e flexor digital caudalmente. Tem sua origem no epicôndilo medial do úmero e sua inserção ocorre por um fino e alongado tendão, na face palmar. Sua função é de flexionar o carpo, as articulações interfalangianas e metacarpofalageana, além de auxiliar na estabilidade (Paranaíba et al., 2012). Configuração semelhante é observada em outros canídeos (Santos et al., 2010b; Rodrigues et al., 2013).

O M. flexor ulnar do carpo (Figuras 3 e 4) de $C$. brachyurus é um músculo alongado, que está dividido em duas cabeças, assim como em cães domésticos (Getty, 2013). A cabeça ulnar (caudal menor) tem sua origem na extremidade proximal da ulna, e estende-se lateralmente ao M. flexor superficial dos dedos. Inserese, após tornar-se um fino tendão, no osso cárpico acessório. Já a cabeça umeral é mais evidente, e origina-se no epicôndilo medial do úmero por fino tendão lateralmente ao M. flexor superficial dos dedos. Seu ventre muscular é protuberante e alongada e insere-se profundamente ao músculo flexor superficial dos dedos por um pequeno tendão no osso cárpico acessório.

O M. flexor profundo dos dedos (Figura 3) localiza-se na região caudal, sendo o mais profundo músculo desse grupo. Assim como em cães-domésticos, possui três cabeças de origem: umeral, radial e ulnar (Zamith, 1946; Getty, 2013). A cabeça umeral, em $C$. brachyurus, é a maior das três e tem sua origem em um tendão encurtado no epicôndilo medial do úmero. Apresenta-se afinado e encontra-se profundo ao M. flexor radial do carpo. A cabeça ulnar, está logo posterior à cabeça umeral e sua origem é na margem caudal da ulna, estando profunda ao M. extensor ulnar do carpo. Por sua vez, a cabeça radial é a menor das três cabeças, estando aderida ao rádio em sua face caudal.

As três cabeças do M. flexor profundo dos dedos, localiza-se na região caudal, sendo o mais profundo músculo desse grupo. Assim como em cães-domésticos, possui três partes de origem: umeral, radial e ulnar (Zamith, 1946; Getty, 2013). A parte umeral, em $C$. brachyurus, é a maior das três e tem sua origem em um tendão curto no epicôndilo medial do úmero. Apresenta-se afinado e encontra-se profundo ao $\mathrm{M}$. flexor radial do carpo. A parte ulnar, está logo posterior à parte umeral e sua origem é na margem caudal da ulna, estando profunda ao M. extensor ulnar do carpo.

O M. flexor profundo têm sua inserção por meio de uma fusão em um único e espesso tendão que se estende na face palmar da mão passando no interior do canal cárpico até alcançar a 


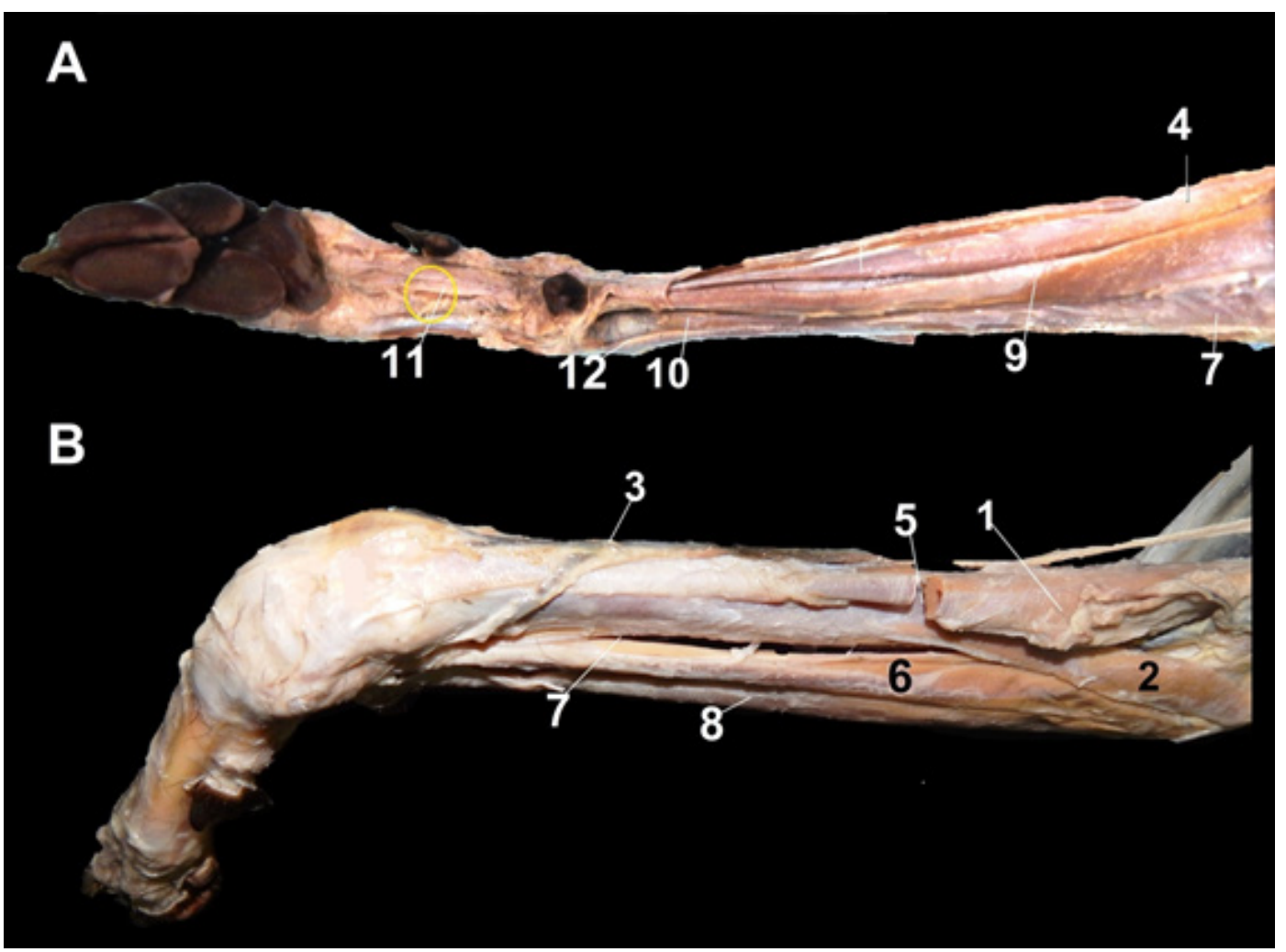

Figura 4: A Antebraço e mão de $C$. brachyurus face caudal e palmar; B Antebraço e mão de $C$. brachyurus vista craniomedial: $1 \mathrm{M}$. extensor radial do carpo; $2 \mathrm{M}$. pronador redondo; $3 \mathrm{M}$. Braquiorradial profundo à veia cefálica;4. M. flexor ulnar do carpo; 5 M. extensor comum dos dedos; 6 M. extensor lateral dos dedos; 7 M. abdutor longo do dedo l; $8 \mathrm{M}$. flexor radial do carpo; 9 M. flexor superficial dos dedos; 10 M. flexor profundo dos dedos; 11 Inserção do M. flexor superficial dos dedos; $12 \mathrm{M}$. pronador quadrado.

inserção nas faces palmares das falanges distais, formando um retináculo flexor para toda a mão. Tal conformação é comum para canídeos em geral, porém a inserção é muito especifica para o lobo-guará, devido a formação desse retináculo no carpo por finos tendões. Acredita-se que essa característica morfológica tenha relação com seu passo compassado digitígrado, no qual tal músculo faz a flexão dos dedos, importante para a corrida e para os eventuais saltos que o lobo-guará executa (St. Clair, 1986; Hildebrand e Goslow, 2006).

O M. pronador quadrado (Figuras 3 e 4) é um fino músculo que está localizado no espaço interósseo antebraquial proximal entre o rádio e a ulna. Sua função é fazer os movimentos de pronação da mão. Segundo Dyce et al., (2010) este músculo é encontrado apenas nos carnívoros.

A mão de $C$. brachyurus tem coxins palmares firmemente ligados às fáscias de inserção dos tendões, dando a essa espécie uma maior estabilidade para sua andadura, movimentos de salto e escalada. Existem cinco músculos com função de auxiliar a flexão e abdução da mão em C. brachyurus, sendo M. interflexor, M. flexor curto dos dedos, M. abdutor curto do dedo I; M. adutor do dedo II e Mm. lumbricais.
O M. interflexor é delgado e está localizado na superfície palmar, superficialmente ao tendão de inserção do músculo flexor digital profundo do carpo. O M. interflexor em carnívoros, segundo Paranaíba et al. (2012), é constituído por feixes longitudinais que têm origem na face palmar do carpo, junto ao músculo flexor profundo, seguindo até os tendões dos flexores superficiais dos dedos, assim como foi observado no lobo-guará.

Os Mm. lumbricais são três pequenos músculos que se localizam entre os tendões flexores profundos dos dedos II ao V, como no cão doméstico (St. Clair, 1986). Os Mm. interósseos são pequenos músculos na superfície palmar que ficam lateralizados junto aos ossos metacárpicos em $C$. brachyurus e sua inserção se dá do II ao IV dedo em suas superfícies palmares.

Os M. abdutor curto do dedo I; M. adutor do dedo II e M. flexor curto do dedo I estão pouco evidentes. Têm suas origens nos ligamentos cárpicos correspondentes e inserem-se nos respectivos dedos e sesamoides proximais.

O Quadro 1 apresenta os pontos de origem e inserção, bem como a inferência da ação dos músculos do antebraço e mão de C. brachyurus, com base nos pontos de fixação, direção de fibras e o que é descrito pela literatura para outros canídeos. 
Quadro 1: Origem, inserção e inferência da ação dos músculos do antebraço e mão de $C$. brachyurus

\begin{tabular}{|c|c|c|c|}
\hline Músculo & Origem & Inserção & Inferência de ação \\
\hline M. extensor radial do carpo & Epicôndilo lateral do úmero & Face lateral do rádio e Metacárpico II & Estender a articulação do carpo \\
\hline M. extensor comum dos dedos & Epicôndilo lateral do úmero & Sulco lateral na epífise distal do rádio & $\begin{array}{l}\text { Estender a articulação dos dedos } \\
\text { II, III, IV, V }\end{array}$ \\
\hline Braquiorradial & $\begin{array}{l}\text { Terço distal da face lateral na crista } \\
\text { supracondilar lateral do úmero }\end{array}$ & Epicôndilo lateral do rádio & Estender o carpo \\
\hline M. supinador & Epicôndilo lateral do úmero & $\begin{array}{l}\text { Face cranial do corpo do osso rádio em } \\
\text { seu terço médio }\end{array}$ & Rotacionar o cotovelo \\
\hline Abdutor longo do dedo I & Margem lateral da ulna, na região interóssea & Metacárpico I superfície dorsal & $\begin{array}{l}\text { Abduzir a articulação metacarpo- } \\
\text { falângica I }\end{array}$ \\
\hline M. extensor dos dedos I e II & $\begin{array}{l}\text { Terço médio da superfície dorsal da ulna, } \\
\text { profundamente aos músculos extensores } \\
\text { carpo }\end{array}$ & $\begin{array}{l}\text { Extremidades distal dos ossos } \\
\text { metacárpicos e nas falanges proximais } \\
\text { dos dedos I e II }\end{array}$ & $\begin{array}{l}\text { Estender a articulação dos dedos } \\
\text { I e II }\end{array}$ \\
\hline M. extensor ulnar do carpo & Epicôndilo Lateral do úmero & $\begin{array}{l}\text { Terço proximal e face lateral do osso } \\
\text { metacárpico } \mathrm{V}\end{array}$ & Estender o metacarpo \\
\hline M. extensor lateral dos dedos & $\begin{array}{l}\text { Epicôndilo lateral do úmero profundo ao } \\
\text { ligamento colateral }\end{array}$ & Falange distal dos dedos III, IV e V & $\begin{array}{l}\text { Estender a articulação dos dedos } \\
\text { II, III, IV, V }\end{array}$ \\
\hline M. pronador redondo & Epicôndilo medial do úmero & $\begin{array}{l}\text { Margem medial do rádio em seu terço } \\
\text { proximal }\end{array}$ & Rotacionar o cotovelo \\
\hline M. flexor superficial dos dedos & Epicôndilo medial do úmero & $\begin{array}{l}\text { Cárpico Acessório e ossos metacárpicos } \\
\text { II, III, IV e V }\end{array}$ & Flexionar a articulação do dedos \\
\hline M. Flexor radial do carpo & Epicôndilo medial do úmero & Face palmar nos Metacárpico II e III & Flexionar a articulação do carpo \\
\hline M. flexor ulnar do carpo & $\begin{array}{l}\text { Cabeça ulnar - extremidade proximal da ulna } \\
\text { Cabeça umeral - epicôndilo medial do úmero }\end{array}$ & Osso cárpico acessório & Flexionar a articulação do carpo \\
\hline M. flexor profundo dos dedos & $\begin{array}{l}\text { Cabeça umeral - epicôndilo medial do úmero } \\
\text { Cabeça ulnar - margem caudal da ulna } \\
\text { Cabeça radial - margem medial do rádio }\end{array}$ & $\begin{array}{l}\text { Canal do carpo na face palmar e nas } \\
\text { falanges distais de cada dedo (exceto I) }\end{array}$ & Flexionar a articulação dos dedos \\
\hline M. pronador quadrado & Espaço interósseo antebraquial proximal & Espaço interósseo antebraquial distal & Pronar da mão \\
\hline M. interflexor & Superfície palmar & Flexor superficial dos dedos & Flexionar a articulação da mão \\
\hline M. flexor curto dos dedos & Tendão do flexor digital & $\begin{array}{l}\text { Ligamentos transverso } \\
\text { metacarpofalângio }\end{array}$ & Flexionar a articulação da mão \\
\hline M. lumbricais & Entre os tendões flexores digitais profundos & $\begin{array}{l}\text { Entre os tendões flexores digitais } \\
\text { profundos }\end{array}$ & Flexionar a articulação da mão \\
\hline Músculos interósseos & Superfície palmar dos metacarpos & $\begin{array}{l}\text { Em cada osso sesamoide da região } \\
\text { palmar }\end{array}$ & $\begin{array}{l}\text { Flexionar a articulação } \\
\text { metacarpofalângea }\end{array}$ \\
\hline Músculo abdutor curto do dedo I & Ligamento cárpico palmar & Sesamoides do dedo I & Aduzir dedo I \\
\hline Músculo Adutor do dedo II & Ligamento cárpico palmar & Dígito IIII & Aduzir o dedo II \\
\hline M. flexor curto do dedo I & Tendão do flexor digital & $\begin{array}{l}\text { Ligamentos transverso } \\
\text { metacarpofalângio }\end{array}$ & Flexionar a articulação do dedo I \\
\hline
\end{tabular}

\section{Considerações finais}

Em C. brachyurus a ulna, o rádio os ossos cárpicos, metacárpicos e falanges têm acidentes bastante específicos, porém com semelhança aos dos cãesdomésticos, de acordo com as comparações procedidas.

Os ossos são alongados e afinados, com acidentes característicos. Tais como, o afinamento da ulna em direção a epífise distal e, ainda com um espaço interósseo largo. Os ossos do carpo são bastante comprimidos e os metacárpicos e falanges são alongados.
Os músculos do antebraço são semelhantes aos dos cãesdomésticos e a outros carnívoros silvestres, porém com a presença do $\mathrm{M}$. Braquiorradial em todos os espécimes dissecados. As inserções dos tendões da mão, em geral, são semelhantes a dos carnívorosdomésticos e a outros animais silvestres. Porém, sua morfologia é diferenciada pelo fato deste animal possuir membros alongados e com habilidades manuais, além de corrida e saltos. Acredita-se que estes achados possam cooperar para pesquisas acerca de tal espécie, e que possa enriquecer a literatura sobre o Chrysocyon brachyurus. 


\section{Referências}

AVERSI-FERREIRA, T.A; VIEIRA, L.G; PIRES, R.M; SILVA, Z e PENHA-SILVA, N. Estudo anatômico dos músculos flexores superficiais do antebraço no macaco Cebus apella. Bioscience Journal, v. 22, n. 1, p. 39-144, 2006.

BORGES, P.L, e TOMÁS, W.M. Guia de rastros e outros vestígios de mamíferos do Pantanal. Corumbá: EMBRAPA Pantanal, p.148, 2004

BRASIL, Ministério do Meio Ambiente. PORTARIA Nº 444, DE 17 DE DEZEMBRO DE 2014. ICMBio. 2014

BUDRAS, K.D; FRICKE, W. Anatomy of the dog: an illustrated text. London, Inglaterra: Mosby-Wolf, 1995, 145 p.

CARVALHO, C.T. Aspectos Faunísticos do Cerrado - O Loboguará - (Mammalia, Canidae). Boletim Técnico (Instituto Florestal, São Paulo), v.21, p.1-16, 1976.

CHIARELLO, A.G; AGUIAR, L.; GREGORIN, R.; MELO, F.R; PAGLIA, A.; RODRIGUES, F.H. Mamíferos Ameaçados de Extinção em Minas Gerais, Brasil. In: G.M. Drummond; A.B.M. Machado; C.S. Martins; M.P. Mendonça; J.R. Stehmann (eds.), Listas Vermelhas das Espécies da Fauna e da Flora Ameaçadas de Extinção em Minas Gerais. Fundação Biodiversitas. Belo Horizonte, MG, 2008.

CONFEDERAÇÃO BRASILEIRA DE CINOFILIA (CBKC) Manual de Estrutura e Dinâmica do Cão, 4. Ed, Rio de Janeiro: CBKC, 2013, $148 \mathrm{p}$.

COSTA, R.C; SCHOSSLER, J.E.W. Fractures treatments of the radius and ulna in dogs and cats: A review. Archives of Veterinary Science, v.7, n.1, p.89-98, 2002.

DIETZ, J.M. Ecology and Social Organization of the Maned Wolf.. Smithsonian Contributions to Zoology. 392: 1- 51 p. 1984

DIETZ, J.M. Chrysocyon brachyurus. Mammalian Species, 234: 1-4 p. 1985

DYCE, K.M; SACK, W.O; WENSING, C.J.G. Tratado de anatomia veterinária. 4 ed. Rio de Janeiro: Elsevier. 2010, 840 p.

EVANS, H.E; DE LA HUNTA, A. Miller guia para dissecação do cão. 3.ed. Rio de Janeiro: Guanabara Koogan, 1994, 197 p.

FERRIGNO, C.R.A; SCHMAEDECKE, A.; TORNI, A.; FANTONI, D.T.; STERRNAN, E.A.; GIGLIO, R.E. . Osteometria proximal da ulna associada a distração do olécrano com utilização de fixador externo linear no tratamento da não união do processo ancôneo no cão. Brazilian Journal of Veterinary Research and Animal Science, v.41, n1, 10-23, 2004.

FRANDSON, R.D; WILKE, W.L; FAILS, A.D. Anatomia e Fisiologia dos Animais de Fazenda, $6^{\mathrm{a}}$ ed, Rio de Janeiro: Guanabara Koogan, 2005, 472p.

GETTY, R. Anatomia dos animais domésticos, $5^{\mathrm{a}}$ ed. Rio de Janeiro: Guanabara Koogan, 2013, 2000 p.

HARTSTONE-ROSE, A.; WERDELIN, L.; DARRYL, J.; BERGER, L. The plio-pleistocene ancestor of wild dogs, Lycaon sekowei $\mathrm{n}$. sp. Journal of Paleontology, v.08, n.3, p. 299-308, 2010.

HILDEBRAND, G.; GOSLOW, G. Análise da Estrutura dos Vertebrados. $2^{a}$ ed. São Paulo: Atheneu, p.500, 2006.

INTERNATIONAL COMMITTEE ON VETERINARY GROSS ANATOMICAL NOMENCLATURE. Nomina anatomica veterinária. 5. ed. (rev.) Knoxville: World Association on Veterinary Anatomist. 2012. $177 \mathrm{p}$.
JOHNSON, A.L. Tratamento de fraturas específicas. In: FOSSUM, T. W. Cirurgia de pequenos animais. 3.ed. Rio de Janeiro: Elsevier. Cap.32, p.1058-1073, 2008.

KÖNIG, H.E; LIEBICH, H.G. Anatomia dos animais domésticos: texto e atlas colorido, 6. ed. Porto Alegre: Artmed, 2016. $890 \mathrm{p}$.

LIMA, V.M; PEREIRA, F.C; PEREIRA, K.F. Estudo morfológico dos músculos do antebraço de mão-pelada, Procyon cancrivorus Cuvier, 1798. Bioscience Journal, v.26 n.1, p.109-114, 2000.

MARTINS, G.S.; LOPES, E.R.; TAQUES, I.I.G.; CORREIA, C.G; MEIRELES, Y.S.; TURBINO, N.C.M.R.; LUCIANA, D.; GUIMARÃES, L.D.; NÉSPOLI, P.B. Aspectos da morfologia radiográfica do esqueleto, tórax e abdome do quati (Nasua nasua Linnaeus, 1766). Pesquisa Veterinária Brasileira, vol.33, n.9, p.1137-1143, 2013.

MORO-RIOS, R.F.; SILVA-PEREIRA, J.F.E.; SILVA, P.W.; MOURA-BRITTO, M.; PATROCÍNIO, D.N.M. Manual de Rastros da Fauna Paranaense. Curitiba: Instituto Ambiental do Paraná, 2008, 70 p.

MOTTA-JUNIOR, J.C.; TALAMONI, S.A.; LOMBARDI, J.Á.; SIMOKOMAKI, K. Diet of the Maned Wolf, Chrysocyon brachyurus, in Central Brazil. Journal of Zoology. v.240, n.1, p.277-284, 1996.

NEUMANN, D.A. Cinesiologia do Aparelho Musculoesquelético - Fundamentos Para a Reabilitação Física. $2^{\mathrm{a}}$

Ed, Amsterdã:Elsevier / Medicina Nacionais, 2011, 260 p.

NOWAK, R.M. Walker's mammals of the world. v. 1, 6 ed. Baltimore and London: The Johns Hopkins University Press, 1999, $836 \mathrm{p}$.

OLIVEIRA, F.S.; CANOLA, J.C.; MACHADO, M.R.F.; CAMARGO, M.H.B. Descrição anátomo-radiográfica do esqueleto apendicular da paca (Agouti paca). Acta Scientiae Veterinariae, v.35, p. 83-87, 2007.

PARANAÍBA, J.F.; HELRIGLE, C.; ARAÚJO, E.A.; PEREIRA, K.F. Aspectos morfológicos da mão e pé de Procyon cancrivorus. Natureza On Line, v.4, n.10, p.165-169, 2012. Disponível em: <http://www.naturezaonline.com.br/>. Acesso em: 17 fev. 2017.

PAULA, R.C.; RODRIGUES, F.H.G.; QUEIROLO, D.; JORGE, R.P.S.; LEMOS, F.G.; RODRIGUES, L.A. Avaliação do estado de conservação do Lobo-guará Chrysocyon brachyurus (Illiger, 1815) no Brasil. Brasília. Biodiversidade Brasileira. v.3, n.1, p.146-159, 2013.

PAULA, R.C.; GAMBARINI, A. Histórias de um lobo. Vinhedo: Avisbrasilis, 2013b. 260 p.

PEREIRA, S.G.; SANTOS, A.L.Q.; BORGES, D.C.S.; RIBEIRO P.R.Q.; SILVA, J,O. Anatomia Óssea E Muscular Da Escapula E Braço De Chrysocyon brachyurus (Carnívora, Canidae). Ciência Animal brasileira, v.17, n.3, p.622-632, 2016.

PINHEIRO, L.L.; BRANCO, E.; SOUZA, D.C.; PEREIRA, H.C.P.; LIMA, A.R. Descrição do plexo braquial do cachorro-do-mato (Cerdocyon thous Linnaeus, 1766). Ciência Animal Brasileira, v.15, n.2, p. 213-219, 2014.

RELVA, C.L.; FERREIRA, D.O.A.; ANTUNES, L.M.M. Bases Anatómicas Para Os Principais Acessos Cirúrgicos Ao Membro Torácico Do Cão. 65 f. Tese (Doutorado) - Curso de Mestrado Integrado em Medicina Veterinária, Ciências Veterinárias, Universidade de Trás-dos-montes e Alto Douro, Vila Real Portugal, 2010. 
RIBEIRO, A.R. Estudo Anatômico do Plexo Braquial do macaco Cebus apella. Origem, composição e ramos resultantes. São Paulo. 2002. Dissertação (Mestrado em Anatomia dos Animais Domésticos) - Faculdade de Medicina Veterinária e Zootecnia Universidade de São Paulo, São Paulo. 2002.

RIBEIRO, P.R.Q.; SANTOS, A.L.Q.; RIBEIRO, L.A.; SOUZA, T.A.M.S.; BORGES, D.C.S.; SOUZA, R.R.; PEREIRA, S.G. Movement anatomy of the gluteal region and thigh of the giant anteater Myrmecophaga tridactyla (Myrmecophagidae: Pilosa). Pesquisa Veterinária Brasileira, v.36, n.6, p.539-548, 2016.

RODDEN, M.; BLAKELY, M.. Manual de manejo de lobo-guará. São Paulo: MWSSP. 2007. 99p.

RODDEN, M.; RODRIGUES, F.; BESTELMEYER, S, Chrysocyon brachyurus. IUCN. Lista Vermelha de Espécies Ameaçadas da IUCN de 2012 Versão 2. 2012

RODRIGUES, H. Técnicas Anatômicas. Juiz de Fora: Universidade Federal de Juiz de Fora, 1973, 218 p.

RODRIGUES, R.G.; FILADELPHO, A.L.A.; GOMES, A.V.; BRICK, A.J. Describe The Arm And Shoulder Muscles Of The Dog Eating Fox Cerdocyon thous. Revista cientifica eletrônica de medicina veterinária, v. 21, p.145-155, 2013.

SANTOS-JUNIOR, I.; RODRIGUES, C.A.; CAMPOS, A.; SANTOS, D. Presença do Músculo Braquioradial em cães. Bioscience. Journal, v.1, n.18, p.79-83, 2002.

SANTOS, A.C.; BERTASSOLI, V.M.; OLIVEIRA, V.C.; CARVALHO, A.F.; ROSA, R.C.; MANÇANARES, C.A.F. Morfologia do ombro, braço e antebraço do quati (Nasua nasua). Biotemas, v.23, n.3, p. 67-173, 2010a.

SANTOS, A.C.; BERTASSOLI, B.M.; ROSA, R.A.; CARVALHO, A.F.; MARÇANARES, C.A.F. Miologia comparada do membro torácico do mão-pelada (Procyon Cancrivorus, g. Cuvier, 1798). Revista da FZVA, v.17, n.2, p. 262-275. 2010b.
SCHEBITZ, H.; WILKENS, H. Atlas de Anatomia Radiográfica do Cão e do Gato. 5 ed. Barueri: Manole, 2000, 244 p.

SERPELL, J. The Domestic Dog; its evolution, behaviour and interactions with people. Cambridge, England: Cambridge University Press, 1995, 267 p.

SHAW, J.H.; CARTER, T.S.; MACHADO-NETO, J.C. Ecology of the Giant Anteater Myrmecophaga tridactyla in Serra as Canastra, Minas Gerais, Brazil: A Pilot Study. In: Evolution and Ecology of Sloths, Armadillos, and Vermilinguas (G. G. Montgomery, ed.). Smithsonian Institution Press, p. 379- 384, 1995.

SILVERO-ZUBIRI, C. In: WILSON, DE; MITTERMEIER, R. Handbook of the Mammals of the World, v.1. Barcelona: Lynx. Capítulo: Family Canidae (Dogs) 2009. 352-448 p.

ST. CLAIR, L.E. Músculos do carnívoro, In: Getty, R. D. V. M. (ed) Anatomia dos animais domésticos, v.2. Guanabara Koogan: Rio de Janeiro, 1996, 1986 p.

STANLEY, H.D.; PETER, C.; GOODY, S.A.; EVANS, A.; NEIL, C.S. Anatomia veterinária do cão e do gato. São Paulo: Editora Manole. 2002. 450 p.

VAZ, M.G.R.; LIMA, A.R.; SOUZA, A.C.B.; PEREIRA, L.C.; BRANCO, E. Estudo morfológico dos músculos do antebraço de cachorro-do-mato-de-orelhas-curtas (Atelocynus microtis) e cachorro-do-mato (Cerdocyon thous). Revista Biotemas, v. 4, n. 24, p.121-127, 2011.

ZAMITH, A.P.L. Lições de osteologia dos animais domésticos. Anais Escola Superior de Agricultura Luiz de Queiroz, v.3, p. 173-270, 1946. 